\title{
INTERACCION DE PROMASTIGOTES DE LEISHMANIA DONOVANI CON GELULAS DE EXUDADO PERITONIAL DE RATONES MEDIANTE LA INFLUENCIA DE LA QUIMOTRIPSINA
}

\author{
Lucila ARCAY (1) \& Elizabeth BRUZUAL (2)
}

\section{R E S U M E N}

Se hace un estudio de la interacción de promastigotes de Leishmania dono. vani con células de exudado peritoneal de ratón ( $c$ e p) mediante la influencia de la quimotripsina. La adhesión de los promastigotes a las $c$ e $p$ fue terminal y marginal, y en observaciones hechas a partir de los 10 minutos de enfrentamiento, esta adhesión fue nula hasta los 30 minutos en el grupo tratado, y sólo a las das horas hubo un pequeño incremento $(2.4 \%)$ con respecto al control. Se observa marcada disminución en todos los parámetro medidos, tales como enlace, penetración, multiplicación intracelular, división de formas flageladas, en el grupo tratado. La quimotripsina favorece la formación de formas intermedias flageladas, heciendose el parásito piriforme y esférico, aparecienđo una forma aberrante de extremo anterior cilindrico que semeja a una forma coanoflagelada. Se sospecha que la enzima reduce efectivamente fragmentos proteicos o péptidos, los cuales pueden haber sido tan pequeños como para esconder a otros ligandos relacionados con la adhesión macrófago-parásito.

UNITERMOS: Calazar - Leishmania donovani - Peritonio - Ratos.

\section{N T R O D U C C I O N}

Siendo los organismos de Leishmania spp., parásitos intracelulares obligados de la serie mononuclear del sistema fagocitico-mononuclear (sistema retículo-endotelial, SRE) en el mamifero hospedador, su capacidad para penetrar a las celulas hospedadoras constituye un paso critico en la patogénesis de la leishmaniasis.

Leishmania donovani es el agente etiológico de la leishmaniasis visceral. El parásito existe bajo dos formas esenciales, el promastigote o forma flagelada que penetra al hospedador vertebrado a través de la picada del vector $\mathrm{PH}$ lebotominae infectado, y el amastigote o forma esferoidal intracelular, que procede de la diferenciación del promastigote cuando éste parasita las células del sistema linfo-macrófago, eva- diendo la acción lisosomal de la célula hospedadora y multiplicándose intracelularmente perdiendo el flagelo. La invasión y multiplicación es primaria y esencialmente dentro de macrófagos de los órganos hematopoyéticos, y en el caso de $\mathbf{L}$. donovani se produce en forma natural, diseminación en varias visceras.

Cuando las leishmanias son introducidas en ei hospedador vertebrado, tanto los macrófagos como los linfocitos se acumulan en el sitio de entrada de los promastigotes (ZUCKERMAN ${ }^{35}$ ). por lo cual estos parásitos interactuan con unos y otros. En la interacción se producen una serie de eventos por medio de los cuales los parásitos terminan alojándose dentro de las células hospedadoras, evadiendo los mecanismos y efec- 
ARCAY, L. \& BRUZUAL, E. - Interaccion de promastigotes de Leishmania donovani con celulas de exudado peritoneal de ratones mediente la innuencia de la quimotripsina. Rev. Inst. Med. trop. São Paulo, 28:145-153, 1986.

tos destructivos de la maquinaria lisosomal, multiplicandose y mostrando fusión con el fagolisosoma (ALEXANDER \& VICKERMAN 2; LEWIS \& PETERS 24; CHANG \& DWYER 13), conociendose también que la rata pinocítica aumenta em macrófagos infectados con leishmania y que las vacuolas parasitóforas presentan propiedades de lisosomas secundarios (CHANG 12).

Utilizando la quimotripsina como agente inespecifico en la infección experimental de ratones y hamsters con $L$. mexicana amazonensis (BRUZUAL \& ARCAY $^{6}$ ) hemos encontrado lesiones extensas y una anatomopatologia con fisionomias distintas a las descritas anteriormente en relación al tactismo en leishmanias productoras de leishmaniasis cutáneas que conducen a la visceralización de una Leishmania sp. dermotropa (GUIMARÃES 16,17,18,19; MEDINA \& ROMERO ${ }^{25}$; COUTINHO \& COELHO ${ }^{10}$; SCHNUR 28; ARCAY et al., 4; OCHOA \& ARCAY ${ }^{26}$; ARCAY ${ }^{3}$ ).

El hecho de que amastigotes procedentes de una leishmaniasis experimental cutánea, se diseminen en las visceras de los animales tratados con quimotripsina, nos indujo a estudiar la interacción de promastigotes con células de exudado peritoneal de ratones (c e p) mediante la acción de la quimotripsina.

Es esencial en la patogénesis de leishmaniasis la capacidad de las especies de Leishmania de adherirse a la superficie de los fagocitos mononucleares, antes de penetrar a estas céluias hospedadoras. Los promastigotes pueden eludir su confrontación inicial con fagocitos mo nonucleares, residiendo temporalmente en otros tipos de células, para transformarse en amastigotes bajo condiciones naturales.

Utilizando un sistema de cultivo in vitro de monocapas celulares de exudado peritoneal de ratón, hemos estudiado la fase de adhesión y de multiplicación de promastigotes de L. donovani procedentes de un cultivo in vitro de una cepa mantenida en Medio Davis, mediante la influencia de la quimotripsina, cuantificando el porcentaje de adhesión de promastigotes libres $y$ de formas flageladas intermedias, multiplicación dentro de las células invadidas, así como cambios morfogénicos presentados en los parásitos de los grupos tratados.

\section{MATERIALES Y METODOS}

Las células de exudado peritoneal de ratón fueron extraidas de acuerdo a la técnica modificada de SUTTER ${ }^{30}$. Ratones blancos de la cepa NMRI se inyectaron diariamente durante 8 dias por via intraperitoneal (ip) con $50 \mathrm{mg} / \mathrm{kg}$ de peso con ácido ascórbico en un volumen de $0.5 \mathrm{ml}$ de agua destilada; al cuarto dia se comenzó a inyectar también $3 \mathrm{ml}$ de solución GKN (solución de cloruro sódico, cloruro de potasio y glucosa) para provocar el proceso inflamatorio. Al cabo de este tiempo se procedió a obtener las c e p para lo cual se anesteciaron los ratones con éter, se les afeitó la región ventral, tórax y abdomen, desinfectándola con alcohol y solución de iodo al $2 \%$.

Se le inyecta a cada ratón 8 a $10 \mathrm{ml}$ de GKN via ip. Se masajea suavemente y se hace una pequeña incisión lateral y longitudinal en la parte inferior del abdomen, para extraer el exudado peritoneal con una jeringa de $10 \mathrm{ml}$, aguja n. 18. Se deshecha el líquido cuando tiene aspecto sanguinolento. Se va colocando el exudado en tubos de centrífuga para ser sometido a $800 \mathrm{rpm}$ durante 10 minutos. Se deshecha él sobrenadante y se lavan las células con GKN fria mediante centrifugación; se repite el lavado y se resuspenden las células en $2 \mathrm{ml}$ de $\mathrm{Me}$ dio Mc Coy's más $10 \%$ de suero fetal de terne ra (SFT). El pH se ajustó a 7.2. Se hace la cuenta celular mediante hemocitómetro y se prepara una suspensión a una concentración de $5 \times 10^{5}$ células $/ \mathrm{ml}$. Se siembran los tubos Leighton con laminilla conteniendn $2 \mathrm{ml}$ de Medio Mc Coy's adicionado con SFT más 0.2 mg de Gentamicina. Se colocan en estufa a $37^{\circ} \mathrm{C}$ en atmósfera de $5 \%$ de $\mathbf{C O}_{2}$. Se incuban durante 12 horas y se cambia el medio antes de sembrar los parásitos.

Promastigotes de $\mathbf{L}$. donovani mantenidos por pases sucesivos en Medio Davis, fueron la. vados dos veces en sol. GKN fria a $2.500 \mathrm{~g} / 4^{\circ} \mathrm{C} /$ 10 minutos. Se resuspendieron en Medio Mc Coy's adicionado de L Glutamina, bicarbonato de sodio, Gentamicina y $10 \%$ SFT. Se contaron los parásitos en cámara hemocitométrica y se utilizaron dos promastigotes/célula (1 x $10^{6}$ promastigotes) en cada tubo Leighton. La esterilización de los medios se realizó a través de membranas Millipore de $0.22 \mu$. 
ARCAY, L. \& BRUZUAL, E. - Interaccion de promastigotes de Leishmania donovani con celulas de exuctaco peritoneal de ratones mediante la influencia de la quimotripsina. Rev. Inst. Med. trop. Săo Paulo, 28:145-153, 1986.

Se establecieron dos grupos en cada experimento: un grupo control sin tratamiento y un grupo experimental tratado con Quimotripsina (Armour) $0.2 \mathrm{ml} /$ tubo en dilución 1:1000, la cual fue administrada en seguida de haber sembrado los parasitos.

De cada grupo se extrajeron dos laminillas en los siguientes intervalos: $10,20,30,45 \mathrm{mi}-$ nutos y 1, 2, 3, 6, 12 y 18 horas. Se fijaron en metanol y se tiñeron por la técnica May Gründwald-Giemsa.

Cada una de las laminillas teñidas fue observada bajo lente de inmersion (1200 X) y se midieron los siguientes parámetros mediante contadora mariual de teclas en 20 campos escogidos al azar: número de células de exudado peritoneal, número de promastigotes libres, número de promastigotes y células flageladas intermedias adheridos a las c e p, número de pa. rásitos libres en proceso de división, número de formas esferoidales, número de nidos de amastigotes (número de $\mathrm{c}$ e $\mathrm{p}$ parasitadas).

\section{RESULTADOS}

Al estuđiar la interación de promastigotes de Leishmania donovani con $\mathrm{c}$ e $\mathrm{p}$ de ratones međiante la influencia de la quimotripsina, aplicando la técnica modificada de SUTTER ${ }^{30}$, hemos medido diferentes parámetros: porcentaje de $\mathrm{c}$ e $\mathrm{p}$ parasitadas (número de nidos de amastigotes por célula invadida); adherencia de promastigotes $\mathrm{y}$ formas flageladas intermedias; porcentaje de formas libres en división; acción de la quimotripsina sobre el número de c e p; modificaciones morfológicas del parásito; tipos de células hospedadoras.

El porcentaje de $\mathrm{c}$ e $\mathrm{p}$ infectadas equivale al número de nidos de amastigotes contenidos áentro de ellas. En el Gráfico 1 podemos ob. servar que en el grupo control este porcentaje se mantuvo en cero en los primeros $10 \mathrm{mi}$ nutos, mientras aue para el grupo tratado fue nulo hasta los 45 minutos, para elevarse ligeramente al $2.8 \%$ a la hora. descender a $2.4 \%$ a las dos horas. para luego caer lentamente a las tres horas hasta cero, manteniendose así hasta las 18 horas de observación. En los controles se inicia la multiplicación intracelular a los 20 minutos $(1.6 \%)$, a los cuarenta y cinco minutos se eleva a $16.8 \%$ manteniendose una curva

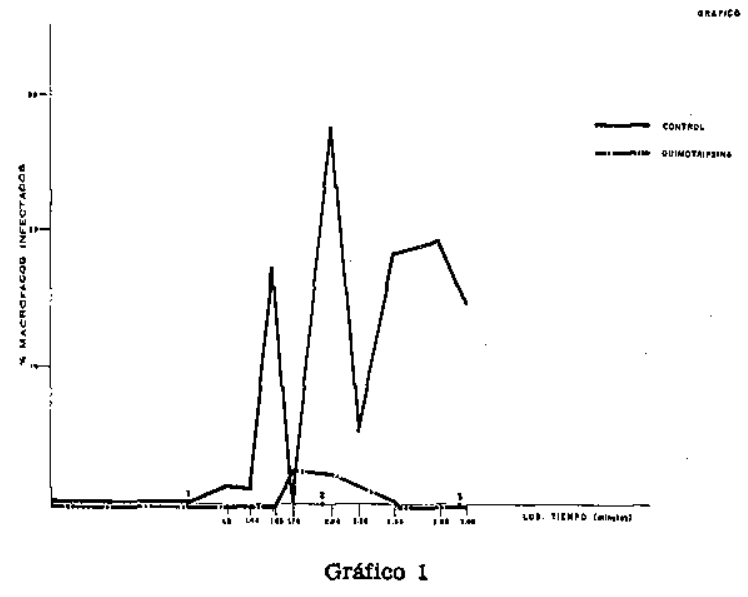

de crecimiento oscilatorio que se incrementa y decrece a la hora, para alcanzar un máximo de $27.4 \%$ a las dos horas, manteniendose a las 18 horas en un $15 \%$ de amastigotes en division.

Calculamos y medimos el porcentaje de formas libres aheridas con respecto al número de c e p (las cuales referimos en nuestros gráficos como macrófagos), observandose que la adhesión de los promastigotes se presenta elevada a los diez minutos de observación en el grupo control $(12 \%)$ mientras que este valor es casi nulo en el grupo tratado hasta los 30 minutos, en donde se manifiesta ligeramente $(1.8 \%)$, desciende a cero $\mathrm{y}$ se mantiene asi casi todo el tiempo, con excepción de a las dos horas en que tiene una pequeña elevación $(2.4 \%)$ por encima del control (Gráfico 2).

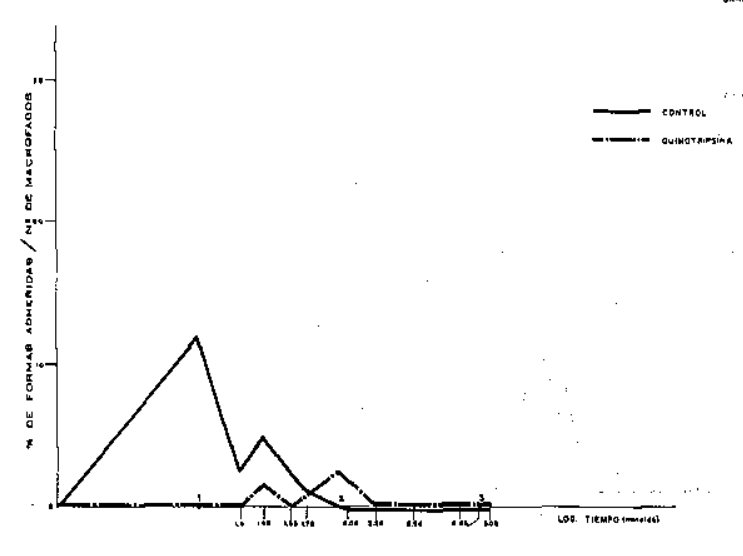

Gránco 2

LOS valores del porcentaje de promastigotes en división con respecto al porcentaje de formas libres flageladas fueron nulos para el gru. 
ARCAY, L. \& BRUZUAL, E. - Interaccion de promastigotes de Leishmania donovani con celulas de exudado peritoneal de ratones mediante la influencia de la quimotripsina. Hev. Inst. Med. trop. Sæ̃o Paulo, 23:145-153, 1986.

po tratado hasta los 45 minutos, para incrementarse al $8,8 \%$ a la hora, descender un poco a las dos horas $(7.5 \%)$ y caer bruscamente a cero hasta las 18 horas. Este parámetro en los controles demuestra un incremento elevado a los veinte minutos $(11.3 \%)$ presentando una curva de crecimiento oscilante parecida al parámetro del control del \% de macrófagos parasitados (Gráfico 3).

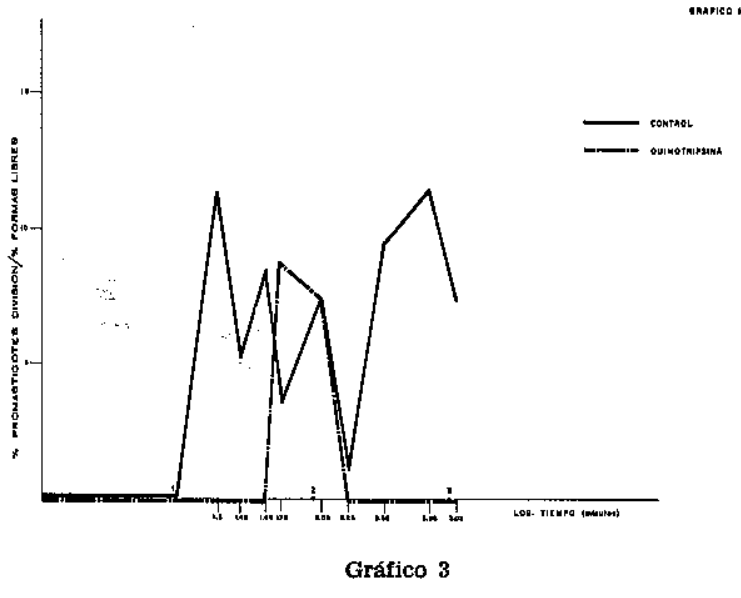

Formas flageladas intermedias piriformes y esféricas en relación al porcentaje de promastigotes alargados, presentan curvas de crecimiento que oscilan en forma parecida a las anteriores, llegando hasta el $100 \%$ en el grupo tratado y en diferentes intervalos, pareciendo que la quimotripsina favorece la diferenciación de promastigotes alargados a formas flageladas in-

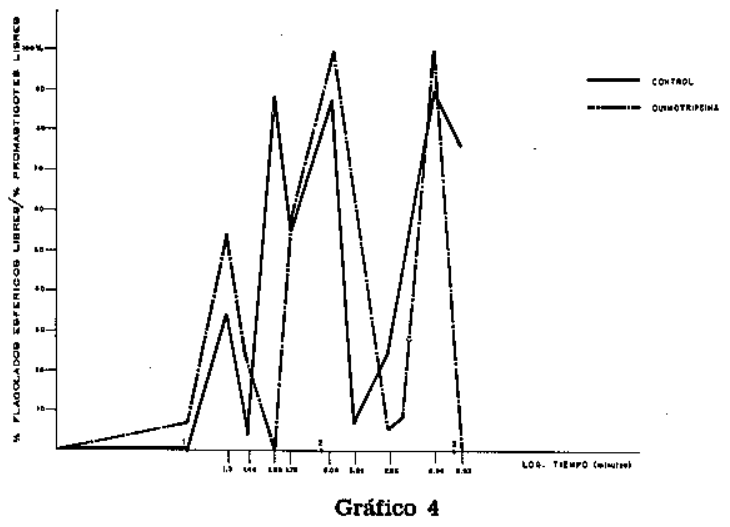

termedias que llegan a ser esferoidales (Gráfico 4).

Con respecto al efecto de la quimotripsina sobre el número de c e p, esta cuenta aparece favorecida por la quimotripsina, con excepción de los primeros diez minutos y los últimos intervalos en que decae a partir de las tres horas para desaparecer Ia monocapa a las 18 horas, mientras que en el grupo control comienza a ascender de nuevo a partir de las dos horas (Gráfico 5).

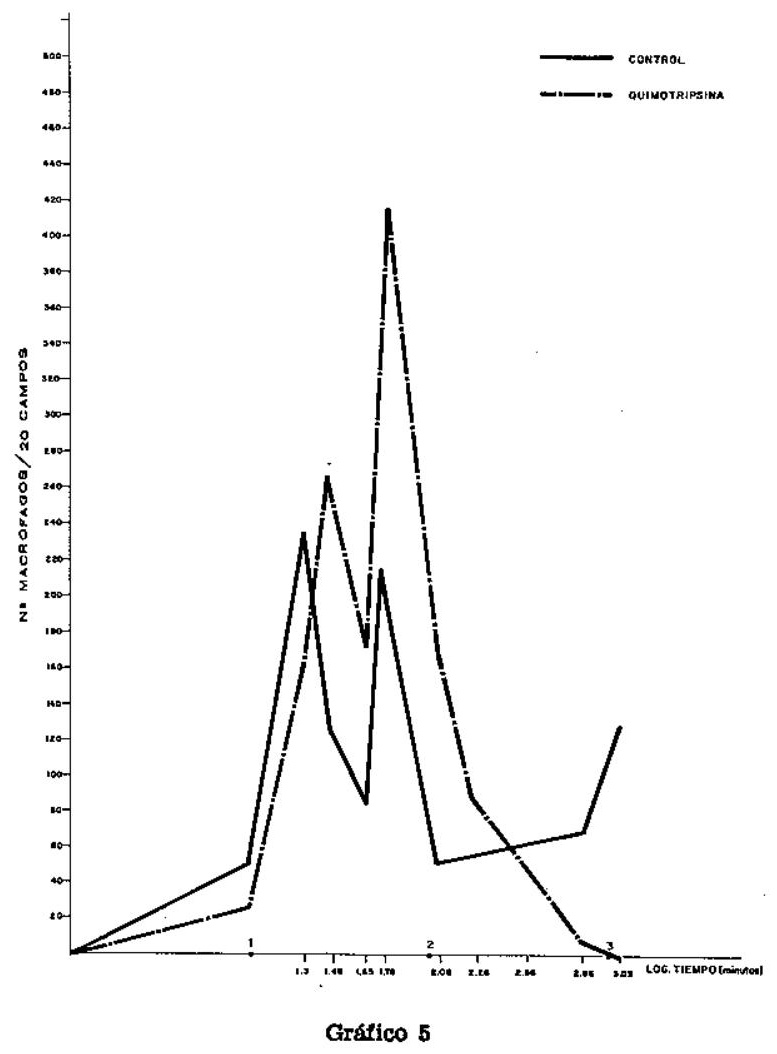

Aplicando la fórmula usada por WYLER y SUZUKI 33 para determinar el porcentaje de probabilidade de adhesión, podemos decir que dicho valor alcanza valores del $100 \%$ en varios intervalos (Gráfico 6). Por encima del 100\% hay una facilitación, $y$ por debajo, hay inhibi. ción de la adhesión.

$$
\% \text { Probabilidad Adhesión }=\frac{\% \text { Adhesión (Control) }-\% \text { Adhesion (Quim.) }}{\% \text { Adhesión (Control) }} 100
$$


ARCAY, L. \& BRUZUAL, E. - Interaccion de promastigotes de Leishmania donovani con celulas de exudado peritoneal de ratones mediante la influencia de la quimotripsina. Rev. Inst. Med. trop. São Paulo, 28:145-153, 1986.

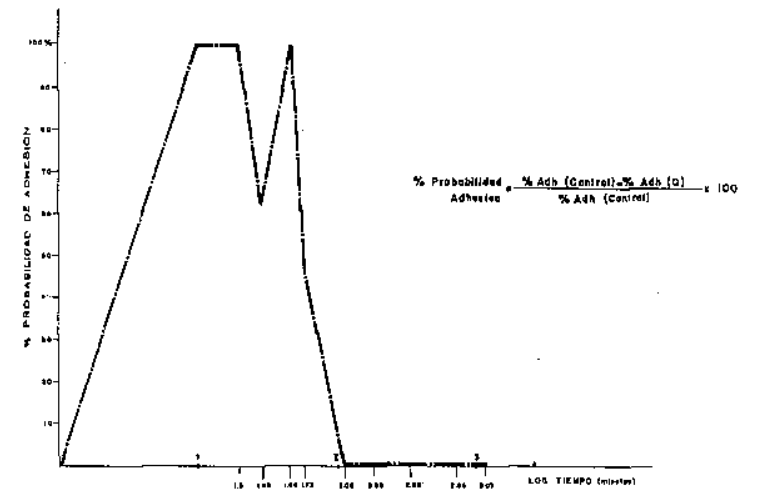

Gráfico 6

\section{Morfogénesis:}

Morfologicamente las formas libres flageladas son alteradas por la acción de quimotripsina, prevaleciendo las formas flageladas esféricas, con modificaciones en cuanto a la división del kinetoplasto $\mathrm{y}$ del núcleo.

En la morfogénesis de los promastigotes de I. donovani mediante la influencia de la quimotripsina, se presenta una forma flagelada con una prolongación cilindrica anterior que le da un aspecto de balón o forma coanoflagelada.

A pesar de que en los gráficos nos referimos a las c e p como macrófagos, no son éstas las células más abundantes en esta monocapa, ya que abundan los linfocitos, en los cuales podemos observar adhesión y atrapamiento por la porción terminal del parásito. También es frecuente la presencia de amastigotes dentro de monocitos, siendo éstas las células por las cuales muestran más afinidad los parasitos leishmánicos. Así mismo, también pudimos ob. servar amastigotes dentro de polimorfonucleares dentro de macrófagos.

\section{DISGUSIÓN}

En general, cuando las leishmanias productoras de leishmaniasis cutáneas son introducidas en hamsters y ratones, se produce una barrera formada por los macrófagos peritoneales que impide su llegada y establecimiento en las visceras, por eso cuando la inoculación es intra. cardíaca, los parásitos se localizan en el bazo durante meses (STAUBER 29; OCHOA \& ARCAY ${ }^{26)}$, y por via endovenosa las leishmanias en ratón se hacen presentes intracelularmente en hígado, bazo y médula osea (WONDE \& I.AMY ${ }^{32}$ ).

Con el uso de la quimotripsina, como agente anti-inflamatorio y capaz de modificar las condiciones del hospedador, hemos observado visceralización en hamsters y ratones inoculados con L. mexicana amazonensis, to cual nos hace suponer que los macrófagos peritoneales no han podido impedir el paso y multiplicación de los parásitos en macrófagos viscerales, lo cual nos ha inducido a estudiar la interacción in vitro de células de exudado peritoneal de ratón con promastigotes de Leishmania mediante la influencia de la quimotripsina.

En el proceso de la interacción leishmaniacélula hospedadora hay que tomar en cuenta una serie de eventos: enlazamiento $\mathrm{y} / \mathrm{o}$ adhesión, penetración a la célula hospedadora para alcanzar el fagosoma, fusión del fagosoma con el fagolisosoma, multiplicación del parásito.

La pérdida de la infectividad de los promastigotes para mamíferos podria reflejar la falla de uno de lo procesos o de varios de ellos, tales como adherencia de los promastigotes a los macrófagos; endocitosis de los parásitos; subsecuente transformación de promastigotes a amastigotes; supervivencia de los parásitos den. tro de los fagolisosomas; replicación, liberación o infección de otros macrófagos (GIANNINI et al. 14).

Gran número de investigadores consideran que los promastigotes se aproximan a los macrófagos por el flagelo primero en la mayoria de los casos, siguiendo luego otras formas de adhesión como la marginal y la terminal, pudiendo ser por cualquier parte del promastigote (ZENIAN \& col. ${ }^{34}$ ). En nuestros experimentos observamos tanto la adhesión terminal como la marginal.

Existe evidencia de que la atracción no es ejercida sobre el promastigote, pero el macrófago busca al parásito, asi como el promastigote activa al complemento con la producción de una sustancia reguladora del complemento $\left(\mathrm{C}_{5 \mathrm{a}}\right)$, la cual es quimiotáxica para los macrófa. gos (BRAY ${ }^{8}$ ). También existe la posibilidad de que el complemento pueda atrapar al promastigote y actua como un puente de atracción para el receptor del complemento sobre la superficie del macrofago (BIANCO \& col. 7; HERMAN 20). 
ARCAY, L. \& BRUZUAL, E. - Interaccion de promastigotes de Leishmania donovani con celulas de exudado peritoneal de ratones mediante la infuencia de la quimotripsina. Rev. Inst. Med. trop. São Paulo, 28:145-153, 1986.

La superficie de las membranas de promastigotes infectivos y no infectivos tiene diferentes patrones de aglutinación de lectinas (HERNANDEZ \& col. 21), lo cual sugiere la presencia de receptores de superfície. Ya que las leishmanias y macrófagos interactuan unos con otros en sus respectivas superficies durante la adnesión, GIANNINI \& col. ${ }^{14}$ consideran como hipótesis que los promastigotes intectivos pueden perder sus receptores para las membranas de los macrófagos y fallar en la adhesión.

Observando los resultados obtenidos para los otros parámetros medidos (promastigotes libres, numero de formas esféricas, número de nidos de amastigotes o porcentaje de macrofagos infectados), los gráficos revelan que los valores del grupo tratado con quimotripsina son siempre inferiores a los del grupo control ( $\sin$ tratamiento).

La interacción de promastigotes y células de exudado peritoneal de ratón refleja su conducta in vivo. La quimotripsina debe actuar sobre los ligandos de superficie de las células del sistema de interacción, impidiendo no sólo la adhesión y enlazamiento, sino la replicación dentro de las células del exudado peritoneal.

La noción de sistemas ligado-receptores para la interacción de membranas plásmicas de microorganismos con células hospedadoras (KEUSCH ${ }^{22}$ ) ha emergido de módulos conceptuales de la interacción de moléculas solubles tales como hormonas, péptidos y moléculas aceptoras sobre las superficie de las células de los mamíferos (CUATRECASAS \& HOLLEMBERG ${ }^{11}$ ). Sin embargo, la adhesión de entidades particulares tales como amastigotes y monocitos, con interacciones altamente complejas posiblemente envuelva una serie de fuerzas electrostáticas e hidrofóbicas (KEUSCH ${ }^{23}$ ).

Nuestros resultados in vivo en ratones $\mathrm{y}$ hamsters infectados experimentalmente con Leishmania mexicana, especie dermotropa, y a los cuales hemos tratado con quimotrinsina. nos producen resultados que van más allá de la visceralización en órganos hematopoyéticos, lo cual podriamos correlacionar con nuestras experiencias de interacción in vitro en monocapas celular de exudado peritoneal, en el sen. tido, que si la quimotripsina actua especificamente sobre los macrófagos peritoneales de esos animales experimentales, despejando esta barrera de macrófagos se permitiria la diseminación del parasito en hígado, bazo, genitales de los machos, riñón y corazón, como revelan nuestros resultados (BRUZUAL \& ARCAY ${ }^{\circ}$ ).

Es importante resaltar que el grado de resistencia de los hospedadores experimentales manifestada in vivo no se correlaciona con el comportamiento in viriro de células de exudado peritoneal de un mismo hospedador resistente. Se ha demostrado la adherencia de promastigotes de L. enrietti (parásito que es especifica del cobayo y que no es infectivo a otros mamiferos) a macrófagos de ratón, en el mismo gra. do o con mayor profusión que los promastigotes de L. tropica, parásito éste al cual el ratón es susceptible. ABAKAROVA \& AKINSHINA 1 consideran que la penetración y la fagocitosis son más activas con macrófagos aislados de animales más susceptibles. En trabajos previos en nuestros laboratorios (BASTARDO \& col.5) hemos demostrado el fenómeno de multiplicación y supervivencia de cepas avirulentas de L. donovani y $\mathbf{L}$. brasiliensis (mantenidas in vitro por muchos años) en células de exudado peritoneal de rata, roedor que es resistente a las especies de Leishmania.

En la patogénesis de leishmaniasis es im. portante conocer la capacidad de Leishmania spp. de adherirse a las superficies de fagocitos antes de entrar a estas células hospedadoras que ellos parasitan. WYLER \& SUZUKI ${ }^{33}$ han investigado la fase de adhesión o enlace in vitro cuantificando el porcentaje de monocitos de sangre humana periferica penetrada usando $\mathrm{Ci}$ tocalacina para prevenir la entrađa del parásito. Estos autores determinan que el pretratamiento de parásitos con tripsina, quimotripsina, pronasa y neuraminidasa redujo el enlazamien. to, especialmente cuando trataban con quimotripsina y pronasa.

Ha sido propuesto que cuando los parásitos son altamente selectivos con respecto a los tipos celulares que ellos invaden, la infección podria depender del reconocimiento de sistemas específicos entre la célula hospedadora y el parásito.

Uno de los conceptos que ha ganado amplia expresión e interés es el que los receptores específicos y ligandos son expresados sobre las 
ARCAY, L. \& BRUZZUAL, E. - Interaccion de promastigotos de Lelshmania donovani con celulas de exudado peritoneal de ratones mediante la influencia do la quimotripsing. Rev. Inst. Med. trop. São Paulo, 28:145-153, 1986.

superficies de la célula hospedadora y el parásito, siendo esencial la interacción de esas moléculas para la infección (SILVERSTEIN 27; KEUSCH 22). Además se reconoce que en la membrana plásmica de macrófagos existen receptores especificos y no específicos para una gran variedad de moléculas inmunes $y$ no inmunes (WERB ${ }^{31}$ ).

El proceso de penetración involucra inte. racción directa sobre dos superficies. En nuestros resultados se observa una disminución brusca del numero de promastigotes viables, to que sugiere el reconocimiento para nuestro sistema de interacción macrófago-parásito. Suponemos que este reconocimiento se deba a la existencia de receptors apropiados en la super. ficie de los macrófagos y/o ligandos específicos en el flagelo, que eniazan a estos receptores.

Nuestros resultados concuerdan con los de WYLER \& SUZUKI ${ }^{33}$, en 10 que se refiere a la actividad de las enzimas, por lo que consideramos responsable a la quimotripsina de los efectos observados.

Las observaciones $\mathrm{y}$ resultados obtenidos sugieren que la adhesión depende de la existencia de los determinantes de proteínas o glucoproteinas presentes. De acuerdo a lo estudios ultraestructurales de WYLER \& SUZUKI 33 no pareciera que esos determinantes estuviesen en la membrana vacuolar derivada del hospedador que se encuentra rodeando al parásito intracelularmente, ya que las microfotografias de los autores revelan que los amastigotes no están rodeados aparentemente por la membrana. Se sospecha que la enzima reduce efectivamente fragmentos proteicos o péptidos, los cuales pueden haber sido tan pequeños como para esconder a otros ligandos relacionados con la adhesión macrófago-parásito. Como resultado de las modificaciones enzimáticas de las superficies celulares que decrecen las ratas de adhesión, podria producirse remoción de ligandos específicos relacionados en el proceso de adhesión, o podrian alterar la superficie celular en una forma no especifica.

BRAY ${ }^{9}$, estudiando la interacción de promastigotes de $\mathbf{L}$. m. mexicana con macrófagos in vitro estudia el fenómeno de adhesión utilizando una serie de enzimas proteoliticas, entre las cuales está la quimotripsina utilizada en dos concentraciones diferentes $(5000 \mu \mathrm{g} / \mathrm{ml}$ y $500 \mu \mathrm{g} / \mathrm{ml}$ a diferentes temperaturas, $4^{\circ} \mathrm{C}$ y $36^{\circ} \mathrm{C}$ ) encontrando que esta enzima afecta profundamente los resultados. Disminuye la adhesión cuando se aplica a los macrófagos en la menor concentración; pero cuando la aplicó al promastigote no obtuvo efecto. En nuestro caso, tratamos con quimotripsina después de haber enfrentado el parásito en forma de promastigote a las células hospedadoras, obteniendo una marcada disminución en todos nuestros parámetros medidos (adhesión, enlace, multiplicación intracelular, división de formas flageladas).

Isa quimotripsina utilizada como agente inespecífico, actua al menos como adyuvante. Los mecanismos de los efectos adyuvantes no han sido elucidados completamente. Ciertos factores tales como la retención de un antígeno incrementado, aumento de la actividad del sistema fagocitico mononuclear (SRE), proliferación linfoides, y la creación de focos inflamatorios, se piensa estén involucrados en la actividad adyuvante.

La complejidad del material celular por si mismo, introduce dentro de tales estudios, una complejidad de sustancias bioquimicas, que pueden tener un efecto en los procesos de sensibilización.

\section{SUMMARY}

\section{"Interaction of Leishmania donovani promastigotes with mouse peritoneal exudate} cells under the influence of the Chymotripsine."

The interaction of promastigotes of Leishmania donovani with mouse peritoneal exudate cells (cep) under the influence of Chymotrip. sine was studied. The promastigote adhered to the $c$ e $p$ terminally and marginally. At 10-30 minutes postchallange, adhesion was absent in the treated group, and only after two hours was there any adhesion $(24 \%$ in comparison with the controls). The experimental group was markedly deficient in all the parameters of activity measured: attachment, penetration, intracellular multiplication and division of flagellates forms in comparison to controls. The Chymotripsine favored the development of intermediate flagellates forms, these being spheroid or pyriform, with example of an aberrant 
ARCAY, I, \& BRUZUAL, E. - Interaccion de promastigotes de Leishmania donovani con celulas de exudado peritoneal de ratones mediante la influencia de la quimotripsina. Rev. Inst. Med. trop. Säo Paulo, 28:145-153, 1986.

form having the anterior end cylindrical similar to a choanoflagellate. It is suspected that the Chymotripsine effectively reduces protein or peptide fragments; these may have been so small as to conceal other ligands associated with macrophage-parasite adhesion.

\section{AGRADECIMIENTO}

Al histotecnólogo del Instituto de Zoologia Tropical de la Universidad Central de Venezuela (UCV) por su asistencia técnica y dibujo 1i. neal de los gráficos. Al Consejo de Des rirollo Cientifico y Humanistico de la $\mathrm{J} \mathrm{CV}$ por la subvención del Proyecto.

\section{REFERENCIAS}

1. ABAKAROVA, E. G. \& AKINSHINA, G. T. - Interaction between macrophages of various origin and Texoploasma gondii under condtions "in vitro". Folla Parasit., 22: 195-200, 1975.

2. ALEXANDER, J. \& VICKERMAN, K. - Fusion of host cell secondary lysosomes with the parasitophorous vacuoles of Leishmanis mexicana infect macrophages. J. Protozool., 22: 502-508, 1975.

3. ARCAY, L. - Influencia de las hormonas sexuales sobre la infeccion experimental producida por una cepa de Leishmania mexicana amazonensis de venezuela. Rev. 1at.-amer. Microbiol., 27: 195-207, 1985.

4. ARCAY-DE-PERAZA, L. OCHOA, N. \& ERCOLI, N. - Nuevas lesiones genitales ocasionadas por Letshmania mexicana amazonensis. Acta cient. venez., 29: 34-41, 1978.

5. BASTARDO, T.; ARCAY, L. \& TEJERO, F. - Interaction of avirulent Leishmania specles with rat peritoneal macrophages. Mem. Inst. Osw. Cruz, 78: 21-26, 1983.

6. BRUZUAL, E. \& ARCAY, L, - Visceralizacion generalizada de Leishmania mexicana amazonensis en hamsters y ratones, bajo la influencia de la quimotripsina, 1985. (en prensa)

7. BIANCO, C.; GRIFFEN, F. N. \& SILVERSTEIN, S. C. - Studies on macrophages complement receptor. Alteration of receptor function upon macrophage activation. J. exp. Med., 141: 1278-1290, 1975.

B. BRAY, R. S. - Leishmania mexicana mexicana: attachment and uptake of promastigotes and macrophages in vitro. 3. Protozool,, 30: 314-322, 1983a.

9. BRAY, R. S. - Lelshmania: Chemotaxic responses of promastigotes and macrophages in vitro. J. Protozool., 30: $322-329$, $1983 \mathrm{~b}$.

10. COUTINHO, E. \& COFLHO, M. V. - Experimental Cutaneous Leishmaniasis. II. The pathology of Leishma- niasis by L. mexicana. Rev. Inst. Med. trop. S. Paulo, 7: 145-155, 1965.

11. CUATRECASAS, P. \& HOLLEMBERG, M. D. - Mem brane receptors and hormone action. Advanc. Protein Chem., 30: 251-451, 1976.

12. CHANG, K. P. - Endocytosis of Leishmania-infected macrophages, fluorometry of pinocytic rate, lysosome phagozome fusioz and intralysosomal pH. In: VAN DEN BOSSCHE, H., ed. - The host invader interplay. Jansen Research Foundation. Amsterdam, Elsevier/ Nrrth-Folland Biomedical Press, 1980. p. 231-234.

13. CHANG, K. P. \& DWYER, D. M. - Leishmania donovani hamster peritoneal macrophage interactions in vitro. J. Parasit., 61 (Suppl.): 71, 1975.

14. GIANNINI, M. S. H.; D'ALESANDRO, P. A.; GARCIA, C. R. \& SARAIVA, E. M. B. - Failure of hamster macrophages to discriminate between infective and non infective promastigotes of Leishmania donovani during attachment in vitro. Infect. Immun. 34: 629-632, 1981.

25. GUIMARAES, F. N. - Leishmaniose experimental. Visceralização de Leishmania braslliensis Vianna, 1911 em hamsters (Cricetus auratus Waterhouse). Brasil méd., 61: Separatim, 47-48, 1947.

16. GUTMARAES, F. N. - Leishmaniose experimental. II. Comportamento de L. brasillensis Vianna $1911 \mathrm{em}$ hamsters (Cricetus (Mesocricetus) auratus Waterhouse). Hospital (Rio de J.), 40; 25-45, $1951 \mathrm{a}$.

17. GUIMARÃES, F. N. - Leishmaniose experimental. III. a) Comportamento de $\mathbf{L}$. brasiliensis em camundango (Mus musculus albina). b) Infecçōes ligeiras em cotton-rats (SIgmodon hispidus). c) Animais refractorios. Hospital (Rio de Y.), 40: 153-162, $1951 \mathrm{~b}$.

18. GUIMARAES, F. N. - Leishmaniose experimental. IV. Reprodução em hamsters (Cricetus auratus) de uma leishmaniose cutânea nódulo-tumoral oriunda da Amazonia. Hospital (Rio de J.), 40: 665-676, 1951c.

19. GUIMARAES, F. N. - Leishmaniose experimental. V. Reprodução em camundongos (Mus musculus alb/ma) de uma leishmaniose cutânea nódulo-tumoral (histiocitoma leishmånico), ocorrendo na Amazonia. Hospital (Rio de J.), 40: 919-931, 1951d.

20. HERMAN, R. - Cytophilic and opsonic antibodies in visceral leishmaniasis in mice. Infect. Imamun., 28: 585-593, 1980 .

21. IERNANDEZ, A. G.; INFANTE, R. B.; IA RIVA, G. de v. O.; DAWIDOWICZ, K. \& CONVIT, J. - The surface membrane of Leishmania. II. Energy dependent agglutination of Leishmania brasiliensis by concanavalin A. Acta clent. venez., 28: 380-384, 2977.

22. KEUSCH, G. T. - Speclfic membrane receptors: patho genetic and therapeutic implications in infections diseases. Rev. infect. Dis., 1: 517.529, 1979.

23. KEUSCH, G. T. - The role of bacterial adherence in infection In: MAGNO, G.; COTRAN, R. S. \& KAAUF. 
ARCAY, L. \& BRUZUAL, E. - Interaccion do prombstigotes de Lelshmanis donovani con celulas de exudado peritoneal de ratones mediante la influencia de la quimotripsina. Rev. Inat. Med. trop. Sāo Paulo, 28:145-153, 1986.

MAN, N., ed. - Current toples in Inflammation. Balti* more, William \& Wilkins, 1982. p. 94-113.

2A. IEWIS, D. H. \& PEIFRS, W. - The resistance of intracellular Leishmanls parasites to digestion by lisosomal enzimes. Ann. trop. Med. Parasit., 71: 295-312, 1977.

25. MEDINA, R. \& ROMERO, J. - Lelshmania pifanoi n. sp., el agente causal de la leishmaniasis tegumen. tarla difusa. Arch. venez. Med. trop., 4: 349-353, 1962.

26. OCHOA DE MACHADO, N. \& ARCAY-DE-PERAZA, L. - Diseminación de heishmania mexicans amazonensis mediante la inoculación intracardiaca, bajo la influen. cia de la acción de la mucins gástrics. Acta cient. vелеz., 29: 119-125, 1978 .

27. SILVERSTEIN, S. C. - Endocytic uptake of particles by mononuclear phagocytes and the penetration of obligate intracellular parasites. Amer. J. trop. Med. Hyg., 26: 161-169, 1977 .

28. SCHNUR. L. F.; ZUCKFRMAN, A. \& MONTILLO, B. - Dissemination of leishmanias to the organs of Syrlam hamsters following intrasplenic inoculation of promastigotes. Exp. Parasit., 34: 432-447, 1973.

29. STAUBERT, L. A. - Leishmanigsis in hamsters. In: Some-physiological aspects and consequences of parasi. tism. Now Brunswick, Rutgers Univ. Press, 1955. p. 76-90.
30. SUTTER, E. - Multiplication of tubercle bactli within mononuclear phagocytes in tissue culture derived from normal animal vaccined with BCG. J. exp. Med., 8\%: 235-245, 1953.

31. WHRB, Z, - Phagocytic cells: chemotaxis and effects funtion of macrophages and granulocytes. In: WITZ, 1. P. \& HANDA, 1. O., ed. -- Contemporary topics in Inmunobiology. New York, Plenum, 1981. p. 109-123.

32. WONDE, M. M. T. \& LAMY, L. - Differences de comportment de Lelshmania donovani dans les macrophages de souris, de rat ot hamster in vivo et in vitro. C.R. Acad. Sci. (Paris) (Serie D) 265: 810-813, 1967

33. WYILER, D. \& SUZUKI, R. - In vitro parasite-monocyte interaction in human leishmaniasis: effect of enzime treatments on attachment. Infect. Immun., 42: $356-361,1983$.

34. ZENIAN, A. ; ROWLES, P. \& GINGELL, D. - Scanning Electron-microscopic study of the uptake of Leishmanis parasites by macrophages. J. Cell. Sel., 39: 187-199, 1979.

35. ZUCKRRMAN, A. - Current status of the immunology of blood and tissue protozoa. I. Leishmania. Exp. Paraslt., 38: 370-400, 1975 .

Recebido para publicação em $17 / 4 / 1985$.

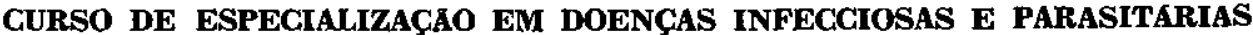

Será realizado nos meses de abril, maio e junho de 1987 o Curso de Especialização em Doenças Infecciosas e Parasitárias, promovido pelo Insttituto de Medicina Tropical de Sāo Paulo, destinado exclusivamente a médicos formados.

O critério de avaliação para aceite dos candidatos será através de "curriculum vitae".

Maiores informações serão divulgadas em ocasiáo oportuna. 